Canadian

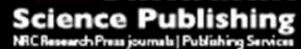

Canadian Journal of Physiology and Pharmacology Revue canadienne de physiologie et pharmacologie

\title{
Interleukin-1beta suppresses the ventilatory hypoxic response in rats via prostaglandin-dependent pathways
}

\begin{tabular}{|r|l|}
\hline Journal: & Canadian Journal of Physiology and Pharmacology \\
\hline Manuscript ID & cjpp-2016-0419.R1 \\
\hline Danuscript Type: & Article \\
\hline Complete List of Authors: & $\begin{array}{l}\text { Aleksandrova, Nina; Pavlov Institute of Physiology RAS, Respiratory } \\
\text { Physiology Lab } \\
\text { Danilova, Galina; Pavlov Institute of Physiology RAS, Respiration } \\
\text { Physiology Lab } \\
\text { Aleksandrov, Vjacheslav; Pavlov Institute of Physiology RAS; Herzen State } \\
\text { Pedagogical University of Russia }\end{array}$ \\
\hline Keyword: & interleukin-13, hypoxia, respiratory chemoreflex, prostaglandin \\
\hline \multicolumn{2}{|c}{} \\
\hline
\end{tabular}

SCHOLARONE $^{\text {tw }}$

Manuscripts 
Interleukin-1beta suppresses the ventilatory hypoxic response in rats via prostaglandindependent pathways

\section{Nina P. Aleksandrova, Galina A. Danilova, and Vjacheslav G. Aleksandrov}

Respiratory Physiology Lab, Pavlov Institute of Physiology RAS, nab. Makarova, 6, SaintPetersburg, 199034, Russian Federation.

Corresponding author: Nina P. Aleksandrova (e-mail: breath@pavlov.infran.ru). 
Abstract: We investigated the effect of the major inflammatory cytokine interleukin-1beta (IL$1 \beta)$ on the ventilatory response to hypoxia. The goal was to test the hypothesis that IL-1 impairs the hypoxic ventilatory response in vivo by indirectly inhibiting respiratory neurons in the brainstem via prostaglandins. Thus, IL-1 $\beta$ was delivered by cerebroventricular injection, and the ventilatory hypoxic response was assessed in anesthetized, spontaneously breathing rats pretreated with or without diclofenac, a nonspecific inhibitor of prostaglandin synthesis. We found that the slope of the ventilatory response to hypoxia decreased almost twofold from $10.4 \pm$ 3.02 to $4.06 \pm 0.86 \mathrm{~mL} \mathrm{~min}^{-1} \mathrm{mmHg}^{-1}(-61 \%) 90$ min after administration of IL-1 $\beta(p<0.05)$. The slope of tidal volume and mean inspiratory flow also decreased from $0.074 \pm 0.02$ to $0.039 \pm$ $0.01 \mathrm{~mL} \mathrm{mmHg}^{-1}(-45 \%, p<0.05)$, and from $0.36 \pm 0.07$ to $0.2 \pm 0.04 \mathrm{~mL} \mathrm{~s}^{-1} \mathrm{mmHg}^{-1}(-46 \%$, $p<0.05)$, respectively. Pretreatment with diclofenac blocked these effects. Thus, the data indicate that IL-1 $\beta$ degrades the ventilatory hypoxic response by stimulating production of prostaglandin. The increase of cerebral levels of IL-1 $\beta$, which is induced by the activation of immune cells in the brain, may impair respiratory chemoreflexes.

Key words: cytokines, interleukin-1 $\beta$, breathing, ventilation, hypoxia, respiratory chemoreflex, prostaglandin. 


\section{Introduction}

Accumulating evidence now suggest that systemic inflammation modulates ventilatory control, the key elements of which include the hypoxic and hypercapnic respiratory chemoreflexes. These elements maintain the homeostasis of gases in arterial blood. In previous studies, we demonstrated that elevated levels of the major inflammatory cytokine interleukin-1 $\beta$ (IL-1 $\beta$ ) in the cerebrospinal fluid reduces the sensitivity of the central chemoreflex to carbon dioxide, and that prostaglandins mediate the effects of IL-1 $\beta$ on the hypercapnic response (Aleksandrova and Danilova 2010; Aleksandrova et al. 2015). Intravenous injection of lipopolysaccharide, and the subsequent release of inflammatory cytokines, were also reported to repress the ventilatory response to hypoxia (Fernandez et al. 2008; Zapata et al. 2011). However, the mechanisms by which inflammation impairs respiratory chemoreflexes are still not clear, and may involve multiple inflammatory molecules that activate central and peripheral chemoreceptors or other respiratory neurons (reviewed in Huxtable et al. 2011).

The hypoxic ventilatory response arises predominantly from peripheral arterial chemoreceptors in the carotid body. Notably, Lam et al. (2008) found that systemic inflammation causes morphological changes in the carotid body. Such changes are associated with changes in the levels inflammatory cytokines, and reduce the chemosensitivity to hypoxia (Gauda et al. 2013). Moreover, glomus cells, which are the primary $\mathrm{O}_{2}$-sensing elements in the carotid body (Zhang et al. 2007), express IL-1 receptor type I and IL-6 receptor $\alpha$ even under normoxic conditions (Wang et al. 2002, 2006). These cells can depolarize in response to hypoxia and release neurotransmitters that activate sensory nerve fibers terminating in the brainstem respiratory center. Taken together, these observations indicate that the carotid body has immunosensory activity, and may modulate the hypoxic ventilatory response during inflammation.

However, a central component in the brainstem complements the peripheral component of the hypoxic chemoreflex. Thus, inflammation-related functional changes in brainstem 
respiratory neurons may also evoke changes in the hypoxic ventilatory response. Indeed, IL-1 $\beta$ has been shown to induce expression of c-fos, a marker of functionally activated neurons, in respiration-related regions in the brainstem, including the nucleus tractus solitarius (Ericsson et al. 1997). However, the nucleus tractus solitarius has been reported to not express IL-1 receptors, and brainstem respiration-related neurons were found to be insensitive to IL- $1 \beta$ in vitro (Olsson et al. 2003). We now present evidence that IL-1 $\beta$ may impair the central hypoxic ventilatory response in vivo through indirect suppression of respiratory neurons in the brainstem via prostaglandins. This phenomenon is demonstrated in anesthetized, spontaneously breathing rats injected with IL-1 $\beta$, and which were pretreated with or without diclofenac, a nonspecific inhibitor of prostaglandin synthesis.

\section{Materials and methods}

\section{Experiments}

Data were collected from 36 tracheostomized rats with mean weight $270 \pm 10 \mathrm{~g}$, and which were anesthetized intraperitoneally with $1000 \mathrm{mg} \mathrm{kg}^{-1}$ urethane, a level sufficient to eliminate pain reflexes. Anesthetic depth was monitored by corneal reflex and response to tactile stimuli. The anaesthetized rats were placed in a stereotactic frame in the supine position with a fixed head. The skin and connective tissues were removed from the skull, a hole was drilled, and a microinjection cannula was placed into the right ventricle of the brain. The stereotaxic coordinates were as follows: $0.8 \mathrm{~mm}$ posterior to bregma, $1.5 \mathrm{~mm}$ lateral from the midline, and $3.7 \mathrm{~mm}$ below the surface of the scull (Paxinos and Watson 1982). All animal procedures were conducted in accordance with the ethical guidelines of the European Community Council Directives 86/609/EEC, and were reviewed and approved by the animal care committee at Pavlov Institute of Physiology RAS. The animals were also cared for in accordance with the Guide to the Care and Use of Experimental Animals by the Canadian Council on Animal Care. 


\section{Ventilation and alveolar gases}

A respiratory flow head connected to a pneumotachometer (AD Instruments ML141 Spirometer, Dunedin, New Zealand) was used to measure peak airflow and respiratory rate. Airflow was integrated to obtain respiratory volume. Minute ventilation was calculated from mean tidal volume and respiratory frequency of ten respiratory cycles, while mean inspiratory flow was calculated as tidal volume divided by inspiratory time. End-tidal partial pressure of oxygen $\left(\mathrm{P}_{\mathrm{ET}} \mathrm{O}_{2}\right)$ was analyzed by a rapid-response quadruple mass spectrometer (Model MC-100, Institute for Analytical Instrumentation, Saint Petersburg, Russia), which was calibrated immediately before and after use with onboard gas mixtures of known composition.

\section{Ventilatory response to hypoxia}

Hypoxic ventilatory response was measured using isocapnic progressive hypoxia rebreathing, following Read (1967), with some modification. Briefly, animals were made to breathe from a bag with $15 \% \mathrm{O}_{2}, 5 \% \mathrm{CO}_{2}$, and $80 \% \mathrm{~N}_{2}$. A gradual decrease in end-tidal $\mathrm{O}_{2}$ was recorded for $4 \mathrm{~min}$, and was monitored on a breath-by-breath basis. $\mathrm{CO}_{2}$ concentration in the bag was kept constant by passing expirations through a $\mathrm{CO}_{2}$-absorbing filter. The response of tidal volume $\left(\mathrm{V}_{\mathrm{T}}\right)$, mean inspiratory flow (Vin), and minute ventilation $\left(\mathrm{V}_{\mathrm{E}}\right)$ to decreased $\mathrm{P}_{\mathrm{ET}} \mathrm{O}_{2}$ was assessed by the linear regression slopes of $\Delta \mathrm{V}_{\mathrm{T}} / \Delta \mathrm{P}_{\mathrm{ET}} \mathrm{O}_{2}, \Delta \mathrm{Vin} / \Delta \mathrm{P}_{\mathrm{ET}} \mathrm{O}_{2}$, and $\Delta \mathrm{V}_{\mathrm{E}} / \Delta \mathrm{P}_{\mathrm{ET}} \mathrm{O}_{2}$ obtained at $\mathrm{P}_{\mathrm{ET}} \mathrm{O}_{2}$ between 80 and $40 \mathrm{~mm} \mathrm{Hg}$. Rectal temperature was measured throughout the experiment, and kept at about $37^{\circ} \mathrm{C}$.

\section{Drug administration}

The animals were divided into four groups. The animals of the first group $(n=9)$ were administered IL-1 $\beta$ (350 ng of human recombinant IL-1 $\beta$ in10 $\mu$ l of saline, Sigma) into the lateral ventricle of the brain. Animals of the second group ( $n=9)$ were first injected intraperitoneally with diclofenac $(0.5 \mu \mathrm{g}$, Belmedpreparaty RUE, Russia) and then IL-1 $\beta$. 
Diclofenac, a non-specific cyclooxygenase inhibitor, was used to investigate the role of the cyclooxygenase pathway in the effects of IL-1 $\beta$. The third group of animals $(n=9)$ was the control, these animals received $10 \mu$ of saline instead of Il-1beta. Fourth group $(n=9)$ was used in order to find possible action of diclofenac on the carotid body. Animals included this group were administered diclofenac intraperitoneally.

The experiment lasted 120 minutes, IL-1 $\beta$ or saline was administered at the thirtieth minute. Diclofenac was injected on the tenth minute of the experiment, that is, 20 minutes before the administration of IL- $1 \beta$, since according to official information the manufacturer the maximum content of diclofenac in blood is reached after 10-20 minutes even after injection. Hypoxic ventilatory response was measured before microinjection of IL-1 $\beta$ or saline and on 20 , 40, 60, and 90 min after administration.

\section{Statistics}

Data are reported as mean $\pm \mathrm{SE}$. Values before and after cerebroventricular injections were compared using Wilcoxon signed rank test and one-way analysis of variance for repeated measures. Differences were considered significant at $p<0.05$. For statistical processing of experimental data STATISTICA 7.0 software package was used.

\section{Results}

\section{Resting breathing}

Cerebroventricular injections of interleukin IL-1 $\beta$, but not saline injections, increased the tidal volume and mean inspiratory flow during resting minute ventilation. Respiratory frequency also tended to increase, but $\mathrm{P}_{\mathrm{ET}} \mathrm{CO}_{2}$ did not change significantly. Breathing indices at baseline and after cerebroventricular injections of saline and IL-1 $\beta$ are listed in Table 1.

\section{Ventilatory response to hypoxia}


During hypoxia, significant correlation was observed between minute ventilation, tidal volume, mean inspiratory flow, and decrease in $\mathrm{P}_{\mathrm{ET}} \mathrm{O}_{2}$, both before and after cerebroventricular injections of IL-1 $\beta$. However, IL-1 $\beta$ decreased the ventilatory response to hypoxia (Fig. 1), and flattened the hypoxic response slopes (Fig. 2A-C), with maximal changes observed 90 min after injection. The slope of the ventilatory response to hypoxia, a measure of the rate at which ventilation rises with decreasing $\mathrm{P}_{\mathrm{ET}} \mathrm{O}_{2}$, decreased more than twofold from $10.4 \pm 3.02 \mathrm{~mL} \mathrm{~min}^{-1}$ $\mathrm{mmHg}^{-1}$ before injection to $4.06 \pm 0.86 \mathrm{~mL} \mathrm{~min}^{-1} \mathrm{mmHg}^{-1}(-61 \%) 90 \mathrm{~min}$ after injection $(p<$ 0.05). The slopes of tidal volume and mean inspiratory flow also decreased from $0.074 \pm 0.02$ to $0.039 \pm 0.01 \mathrm{~mL} \mathrm{mmHg}^{-1}(-45 \%, p<0.05)$, and from $0.36 \pm 0.07$ to $0.2 \pm 0.04 \mathrm{~mL} \mathrm{~s}^{-1} \mathrm{mmHg}^{-1}$ $(-46 \%, p<0.05)$, respectively (Fig. 3). In contrast, cerebroventricular injection of saline did not affect response slopes. Collectively, the data indicate that elevated IL-1 $\beta$ in the brain decreases the ventilatory response to hypoxia, i.e. the inflammatory cytokine depresses the central component of the hypoxic chemoreceptor control of breathing.

\section{Ventilatory response to hypoxia after diclofenac pretreatment}

The effect of IL-1 $\beta$ on the ventilatory hypoxic response was blocked in rats pretreated with diclofenac, a nonspecific cyclooxygenase inhibitor (Fig. 1). In particular, IL-1 $\beta$ did not significantly change either the position or the slope of the ventilation- $\mathrm{P}_{\mathrm{ET}} \mathrm{O}_{2}$ line when administered after an intraperitoneal injection of diclofenac (Fig. 2D-F). Similarly, the relationship between $\mathrm{P}_{\mathrm{ET}} \mathrm{O}_{2}$ and tidal volume or mean inspiratory flow did not significantly change from baseline (Fig. 3).

\section{Discussion}

The data demonstrate a marked attenuation in the hypoxic ventilatory response after cerebral IL-1 $\beta$ is artificially elevated in anesthetized rats. Thus, IL-1 $\beta$ appears to modulate not only peripheral chemoreceptors (Fernandez et al. 2008; Wang et al. 2002; Zhang et al. 2007; 
Zapata et al. 2011), but also central component of respiratory chemoreflexes. The main direction of the flow of cerebrospinal fluid is: lateral ventricle - openings monrovi - III ventricle - Silvius aqueduct - fourth ventricle - hole Luski and Magendie - a big cistern and outer subarachnoid space of the brain, the central canal and subarachnoid space of the spinal cord - the ultimate cistern. The NTS is the most accessible target for drugs contained in the cerebrospinal fluid because it is located at the bottom of the fourth ventricle near its surface. Therefore, we can assume that IL-1 $\beta$ which was injected in the lateral ventricle was reached the bottom of the fourth ventricle and could exert their effects on neurons of the NTS. Because the primary afferents arising from the peripheral chemoreceptors terminate within the NTS it could be expected that the cerebroventricular injection of IL-1 $\beta$ would lead to altered sensitivity to hypoxia. We believe that cerebral IL-1 $\beta$ indirectly depresses the hypoxic ventilatory response by inhibiting respiration-related neurons in the brainstem, such as those in the nucleus tractus solitarius and the rostral ventrolateral medulla. Consequently, the same hypoxic stimulus might elicit less response from these neurons in conditions of elevated IL-1 $\beta$ than in normal conditions. In turn, desensitization of the central inspiratory activity would decrease the efferent activation of spinal respiratory motoneurons, and thereby suppress the generation of force from inspiratory muscle contractions in response to hypoxia, as well as lower the inspiratory driving pressure. Tidal volume and ventilatory hypoxic response would also decrease as a result. Similarly, we have previously demonstrated that cerebral IL-1 $\beta$ also inhibits the hypercapnic ventilatory response (Aleksandrova and Danilova 2010; Aleksandrova at al. 2015). Taken together, our studies suggest that elevated cerebral IL-1 $\beta$ due to inflammation may result in hypoxemia and hypercapnia in the absence of natural compensatory reactions that increase ventilation. Indeed, IL-1 $\beta$ may impair respiration during infection (Hofstetter 2007; Olsson 2003).

We also now demonstrate that cerebral IL-1 $\beta$ depresses the hypoxic chemoreflex via cyclooxygenase, indicating that endogenous prostaglandins may modulate brainstem respiratory neurons during hypoxia, in line with previous studies. For example, IL-1 $\beta$ is already known to 
elicit cyclooxygenase activity and release of multiple secondary mediators, including prostaglandins. Further, Graff and Gozal (1999) reported that IL-1 $\beta$ induces ventilatory effects via eicosanoid-dependent mechanisms. Similarly, we previously demonstrated that inhibiting prostaglandin synthesis with diclofenac clearly blocks the effects of IL-1 $\beta$ on breathing patterns and on the hypercapnic ventilatory response in adult rats (Aleksandrova et al. 2015). $\mathrm{PGE}_{2}$ has also been shown to mediate the anoxic ventilatory effects of IL-1 $\beta$, while indomethacin has been shown to mitigate the adverse effects of IL-1 $\beta$ on hypoxic gasping and anoxic survival in neonatal rats (Hofstetter et al. 2007; Olsson et al. 2003). In addition, it was shown that intravenous administration of endotoxin not only elicited release of inflammatory cytokines, but also altered the respiratory motor output and the cyclooxygenase pathway (Preas et al. 2001).

Stimulation of prostaglandin synthesis appears to be a fundamental and specific mechanism by which IL-1 $\beta$ modulates neuronal function, including in respiration. For instance, IL-1 $\beta$ induces release of cyclooxygenase- 2 and $\mathrm{PGE}_{2}$ in glial and neuronal ganglion cells cultured from rat trigeminal ganglia (Neeb et al. 2011). Our own experiments with diclofenac suggest that IL-1 $\beta$ depends on a similar mechanism to elicit respiratory effects in the brainstem, presumably via glial and neural cells in respiration-related units and that express receptors for IL-1. Upon stimulation, these cells would release prostaglandins into the extracellular space, and thereby stimulate neurons with $\mathrm{PGE}_{2}$ receptors such as EP3R. Indeed, EP3R is strongly expressed in respiration-related tissues of the brainstem such as the NTS and RVLM (Ek et al. 2000; Nakamura et al. 2000). Accordingly, IL-1 $\beta$ was shown to inhibit autoresuscitation after hypoxic apnea in wild-type mice, but not in mice lacking EP3R (Hofstetter et al. 2007).

At present, prostaglandins are believed to inhibit respiration. For instance, $\mathrm{PGE}_{2}$ has been shown to depress breathing in vivo in fetal and newborn sheep, and to inhibit respiration-related neurons in vitro (Guerra et al. 1988; Olsson et al. 2003). It was also shown that $\mathrm{PGE}_{2}$ injection into the rat right lateral ventricle induces expression of c-fos in the nucleus of the solitary tract and in the ambiguus nucleus (Lacroix et al. 1996). These are anatomic evidence that central 
injection of $\mathrm{PGE}_{2}$ evokes selective and specific expression of c-fos in brain structures that regulate respiration. In our own experiments, the hypoxic response also degraded within 30-40 minutes after intraventricular administration of IL-1 $\beta$.

In conclusion, IL-1 $\beta$ appears to be an intercellular messenger molecule that links central and peripheral ventilatory control to immune activity. In particular, IL-1 $\beta$ suppresses respiratory chemoreflexes by inducing production of prostaglandins. Increase cerebral levels of this cytokine, which is induced by the activation of immune cells in the brain may impair respiratory chemoreflexes at the level of the brain stem. We also conclude that the adverse influence of IL-1 $\beta$ on the respiratory chemoreflexes is mediated by activation of endogenous prostaglandin production.

\section{Acknowledgment}

The study was supported by the Russian Science Foundation (Grant No. 15-15-00119).

\section{References}

Aleksandrova, N.P., and Danilova, G.A. 2010. Effect of intracerebroventricular injection of interleukin-1-beta on the ventilatory response to hyperoxic hypercapnia. Eur. J. Med. Res. 15 Suppl. 2: 3-6.

Aleksandrova, N.P., Danilova, G.A., and Aleksandrov V.G. 2015. Cyclooxygenase pathway in modulation of the ventilatory response to hypercapnia by interleukin- $1 \beta$ in rats. Respir. Physiol. Neurobiol. 209: 85-90.

Ek, M., Arias, C., Sawchenko, P., and Ericsson-Dahlstrand, A. 2000. Distribution of the EP3 prostaglandin $\mathrm{E}(2)$ receptor subtype in the rat brain: relationship to sites of interleukin-1induced cellular responsiveness. J. Comp. Neurol. 428(1): 5-20. 
Ericsson, A., Arias, C., and Sawchenko, P.E. 1997. Evidence for an intramedullary prostaglandin-dependent mechanism in the activation of stress-related neuroendocrine circuitry by intravenous interleukin-1. J. Neurosci. 17(18): 7166-7179.

Fernández, R., González, S., Rey, S., Cortés, P.P., Maisey, K.R., Reyes, E.P., et al. 2008. Lipopolysaccharide-induced carotid body inflammation in cats: functional manifestations, histopathology and involvement of tumour necrosis factor-alpha. Exp. Physiol. 93(7): 892907.

Gauda, E.B., Shirahata, M., Masona, A., Pichard, L.E., Kostuk, E.W., and Chavez-Valdeza, R. 2013. Inflammation in the carotid body during development and its contribution to apnea of prematurity. Respir. Physiol. Neurobiol. 185(1): 120-131.

Graff, G.R., and Gozal, D. 1999. Cardiorespiratory responses to interleukin-1beta in adult rats: role of nitric oxide, eicosanoids and glucocorticoids. Arch. Physiol. Biochem. 107(2): 97112.

Guerra, F., Savich, R.D., Wallen, L.D., Lee, C.H., Clyman, R.I., Mauray, F.E., et al. 1988. Prostaglandin E2 causes hypoventilation and apnea in newborn lambs. J Appl. Physiol. 64(5): 2160-2166.

Hofstetter, A.O., Saha, S., Siljehav, V., Jakobsson, P.J., and Herlenius, E. 2007. The induced prostaglandin E2 pathway is a key regulator of the respiratory response to infection and hypoxia in neonates. Proc. Natl. Acad. Sci. U. S. A. 104(23): 9894-9899.

Huxtable, A.G., Vinit, S., Windelborn, J.A., Crader, S.M., Guenther, C.H., Watters, J.J., et al. 2011. Systemic inflammation impairs respiratory chemoreflexes and plasticity. Respir. Physiol. Neurobiol. 178(3): 482-489.

Lacroix, S., Valliéres, L., and Rivest, S. 1996. C-fos mRNA pattern and corticotropin-releasing factor neuronal activity throughout the brain of rats injected centrally with a prostaglandin of E2 type. J. Neuroimmunol. 70(2): 163-179. 
Lam, S.Y., Tipoe, G.L., Liong, E.C., and Fung, M.L. 2008. Chronic hypoxia upregulates the expression and function of proinflammatory cytokines in the rat carotid body. Histochem. Cell Biol. 130(3): 549-559.

Nakamura, K., Kaneko, T., Yamashita, Y., Hasegawa, H., Katoh, H., and Negishi, M. 2000. Immunohistochemical localization of prostaglandin EP3 receptor in the rat nervous system. J. Comp. Neurol. 421: 543-569.

Neeb, L., Hellen, P., Boehnke, C., Hoffmann, J., Schuh-Hofer, S., et al. 2011. IL-1ß stimulates COX-2 dependent $\mathrm{PGE}_{2}$ synthesis and CGRP release in rat trigeminal ganglia cells. 2011. PLoS One, 6(3): e17360.

Olsson, A., Kayhan, G., Lagercrantz, H., and Herlenius, E. 2003. IL-1 beta depresses respiration and anoxic survival via a prostaglandin-dependent pathway in neonatal rats. Pediatr. Res. 54(3): 326-331.

Paxinos, G., and Watson, C.R. 1982. The rat brain in stereotaxic coordinates. London. Academic Press. 456 pp.

Preas, H.L. 2nd, Jubran, A., Vandivier, R.W., Reda, D., Godin, P.J., Banks, S.M., et al. 2001. Effect of endotoxin on ventilation and breath variability: role of cyclooxygenase pathway. Am. J. Respir. Crit. Care Med. 164(4): 620-626.

Read, D.J. 1967. A clinical method for assessing the ventilatory response to carbon dioxide. Australas Ann. Med. 16(1): 20 - 32 .

Tai, T. C., and S. L. Adamson. Developmental changes in respiratory, febrile, and cardiovascular responses to PGE2 in newborn lambs. Am. J. Physiol. 278: R1460-R1473, 2000.

Wang, X., Wang, B.R., Duan, X.L., Zhang, P., Ding, Y.Q., Jia, Y., et al. 2002. Strong expression of interleukin-1 receptor type I in the rat carotid body. J. Histochem. Cytochem. 50(12): $1677-1684$ 
Wang, X., Zhang, X.J., Xu, Z., Li, G.L., Ju, G., and Wang, B.R. 2006. Morphological evidence for existence of IL-6 receptor alpha in the glomus cells of rat carotid body. Anat. Rec. A Discov. Mol. Cell. Evol. Biol. 288(3): 292-296.

Zapata, P., Larraín, C., Reyes, P., and Fernández, R. 2011. Immunosensory signalling by carotid body chemoreceptors. Respir. Physiol. Neurobiol. 178(3): 370-374.

Zhang, X.J., Wang, X., Xiong, L.Z., Fan, J., Duan, X.L., and Wang, B.R. 2007. Up-regulation of IL-1 receptor type I and tyrosine hydroxylase in the rat carotid body following intraperitoneal injection of IL-1beta. Histochem. Cell Biol. 128(6): 533-540. 


\section{Figure captions}

Fig. 1. Effect of IL-1 $\beta$ on the ventilatory hypoxic response. Inspiratory pneumotachogram during normoxic breathing without IL-1 $\beta$ and diclofenac (A), and during hypoxic breathing (B-D). Ventilatory response to hypoxia decreased after cerebroventricular administration of IL-1 $\beta$ without diclofenac pretreatment (C), but not after IL-1 $\beta$ injection with diclofenac pretreatment (D). The panels are representative traces from animals of different experimental groups: placebo (B), IL-1 $\beta$ (C) and IL-1 $\beta$ with diclofenac (D) groups. The panel A is representative basal trace from animal without any treatments.

Fig. 2. Ventilatory response to hypoxia in a representative animal before (solid line) and 90 min after (dashed line) cerebroventricular administration of IL-1 $\beta$ with (A-C) or without (D-F) diclofenac pretreatment. IL-1 $\beta$ treatment without diclofenac decreased the slope of minute ventilation, mean inspiratory flow, and tidal volume response, whereas IL-1 $\beta$ treatment with diclofenac did not change the ventilatory response.

Fig. 3. Time course of the ventilatory response to hypoxia, as measured 20, 40, 60, and 90 min after cerebroventricular administration of IL-1 $\beta$ with (hatched bars) or without (open bars) diclofenac pretreatment. Data are mean \pm SEM, with baseline set at $100 \%$. ${ }^{*}, p<0.05$ vs. baseline. 
Table 1. Effects of IL-1 $\beta$, saline and diclofenac on breathe pattern

\begin{tabular}{|c|c|c|c|c|c|c|c|c|c|}
\hline \multirow[b]{3}{*}{$\mathrm{V}_{\mathrm{E}}\left(\mathrm{mL} \min ^{-1}\right)$} & \multicolumn{3}{|c|}{ Interleukin-1 $\beta$} & \multicolumn{3}{|c|}{ Saline } & \multicolumn{3}{|c|}{ Diclofenac } \\
\hline & Baseline & $40 \mathrm{~min}$ & $60 \mathrm{~min}$ & Baseline & $40 \mathrm{~min}$ & $60 \mathrm{~min}$ & Baseline & $40 \mathrm{~min}$ & $60 \min$ \\
\hline & $104 \pm 9,0$ & $126 \pm 3,7^{* *}$ & $131 \pm 5,4^{* *}$ & $95 \pm 8,2$ & $104 \pm 10,5$ & $94 \pm 10,5$ & $110 \pm 8,2$ & $117 \pm 6,5$ & $110 \pm 7,8$ \\
\hline $\mathrm{V}_{\mathrm{T}}(\mathrm{mL})$ & $1,0 \pm 0,05$ & $1,13 \pm 0,06^{*}$ & $1,17 \pm 0,04^{*}$ & $0,9 \pm 0,14$ & $1,0 \pm 0,08$ & $1,0 \pm 0,12$ & $1,1 \pm 0,05$ & $1,12 \pm 0,05$ & $1,1 \pm 0,04$ \\
\hline $\mathrm{f}$ (breaths $\min ^{-1}$ ) & $109 \pm 6,0$ & $117 \pm 6,8$ & $118 \pm 6,4$ & $104 \pm 8,0$ & $101 \pm 10,4$ & $94 \pm 2,6$ & $105 \pm 7,2$ & $107 \pm 6,1$ & $107 \pm 5,9$ \\
\hline $\mathrm{V}_{\text {in }}\left(\mathrm{mL} \mathrm{s}^{-1}\right)$ & $3,7 \pm 0,27$ & $4,4 \pm 0,12^{*}$ & $4,5 \pm 0,19^{*}$ & $3,7 \pm 0,31$ & $3,8 \pm 0,10$ & $3,9 \pm 0,11$ & $3,8 \pm 0,3$ & $4,1 \pm 0,28$ & $4,0 \pm 0,3$ \\
\hline $\mathrm{P}_{\mathrm{ET}} \mathrm{CO}_{2}(\mathrm{~mm} \mathrm{Hg})$ & $34 \pm 3$ & $30 \pm 3$ & $30 \pm 3,5$ & $34 \pm 2,1$ & $34 \pm 2,8$ & $31 \pm 2,3$ & $32 \pm 3,0$ & $30 \pm 2,8$ & $31 \pm 3,5$ \\
\hline
\end{tabular}

$\mathrm{V}_{\mathrm{E}}$ - minute ventilation, $\mathrm{V}_{\mathrm{T}}$ - tidal volume, $\mathrm{f}$ - respiratory frequency, $\mathrm{V}_{\mathrm{in}}$ - mean inspiratory flow, $\mathrm{P}_{\mathrm{ET}} \mathrm{CO}_{2}$ - the end-tidal partial pressure of carbon dioxide. Values are means \pm SEM. ${ }^{*} p<0,05$ and $* * p<0,01$ for the comparison with baseline. 
Normoxia Hypoxia $\left(\mathrm{P}_{\mathrm{ET}} \mathrm{O}_{2}=40 \mathrm{mmHg}\right)$

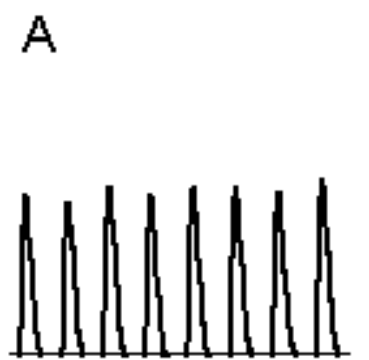

Before IL-1 $\beta$

B

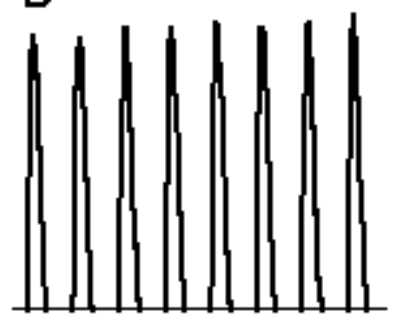

Before IL-1 $\beta$
C

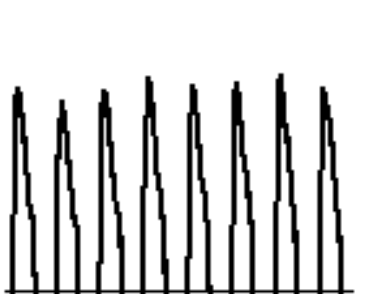

After IL-1及

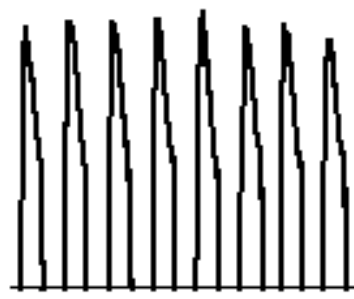

After IL-1B with diclofenac
$2 m L \cdot s-1$

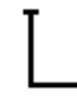

1s 

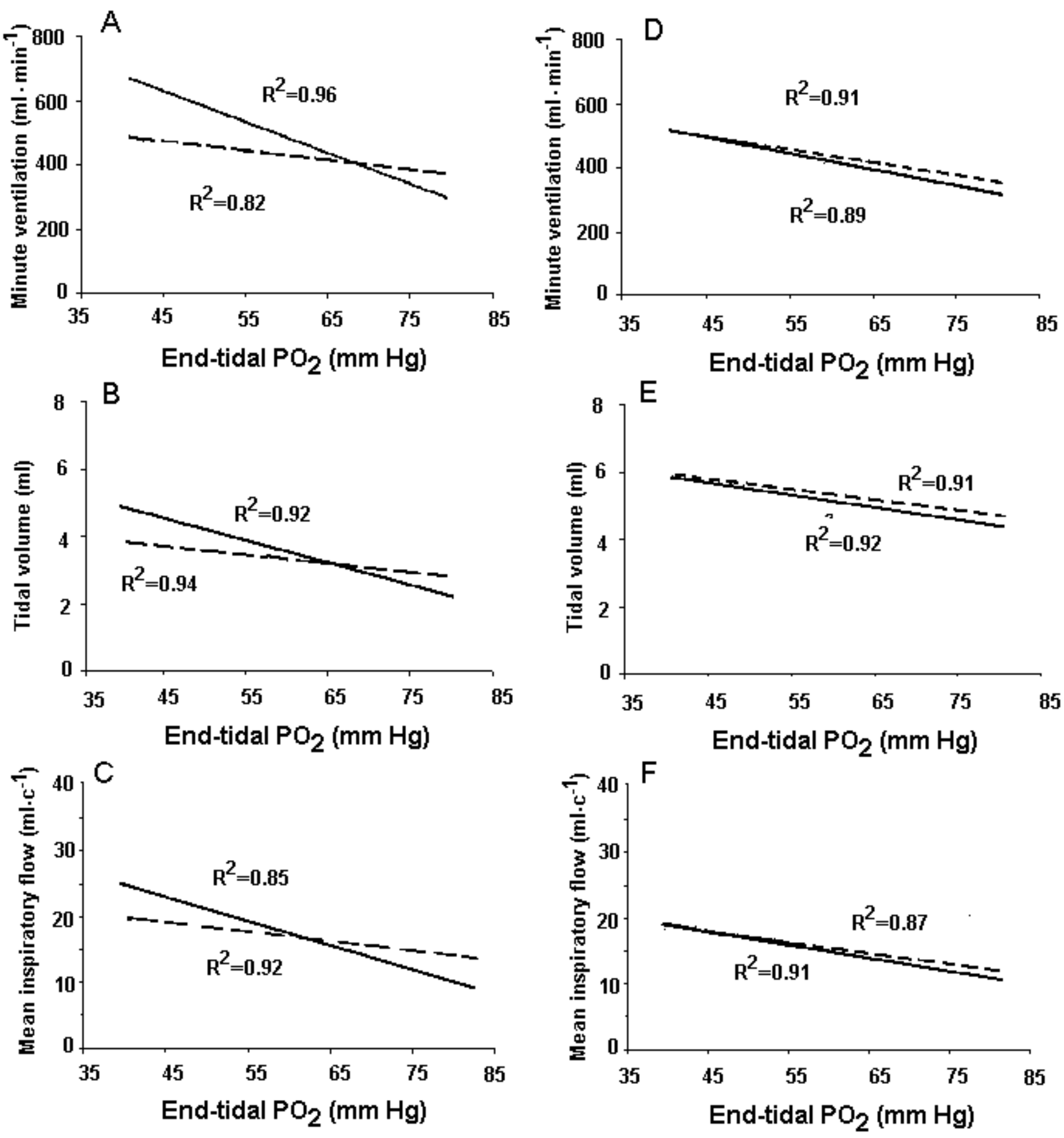

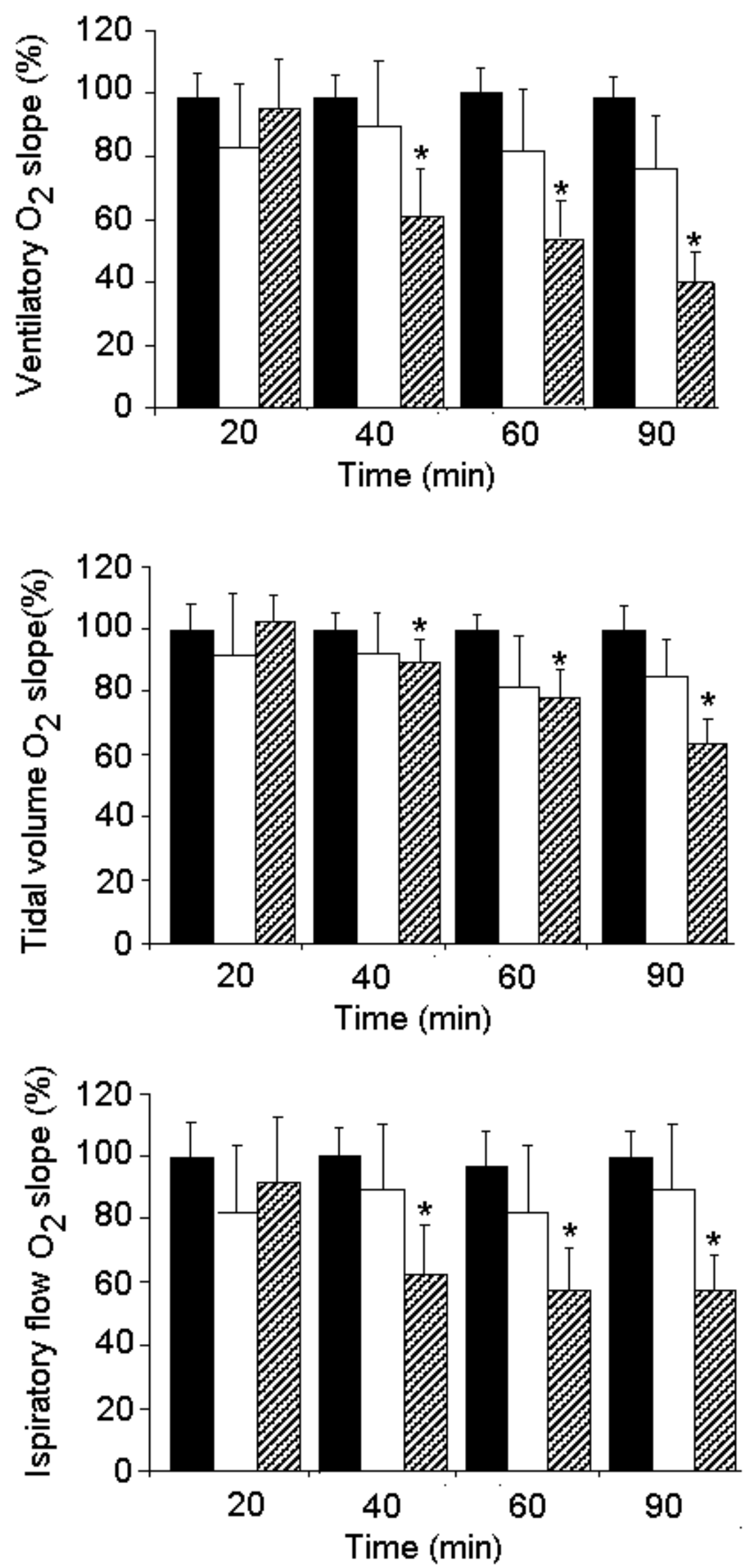